\title{
Progress of Composite Fabrication Technologies with the Use of Machinery
}

\author{
Byung-keun Choi ${ }^{1}$, Yun-hae Kim ${ }^{2 *}$, Jin-cheol Ha ${ }^{2}$, Jin-woo Lee ${ }^{2}$, Jun-mu Park ${ }^{2}$, \\ Soo-jeong Park ${ }^{2}$, Kyung-man Moon ${ }^{2}$, Won-jee Chung ${ }^{3}$ and Man-soo Kim ${ }^{3}$ \\ ${ }^{1}$ Jet Korea Industrial Corporation, Gimhae-si, Gyeongsangnam-do, Korea \\ 2 Department of Marine Equipment Engineering, Korea Maritime University, Youngdo-ku, Busan, Korea \\ 3 Department of Mechanical Design \& Manufacturing, Changwon National University, Chanwon-si, Gyoungnam-do, Korea
}

(Manuscript Received June 21 2012; Revised July 16, 2012; Accepted August 8, 2012)

\begin{abstract}
A Macroscopic combination of two or more distinct materials is commonly referred to as a "Composite Material", having been designed mechanically and chemically superior in function and characteristic than its individual constituent materials. Composite materials are used not only for aerospace and military, but also heavily used in boat/ship building and general composite industries which we are seeing increasingly more. Regardless of the various applications for composite materials, the industry is still limited and requires better fabrication technology and methodology in order to expand and grow. An example of this is that the majority of fabrication facilities nearby still use an antiquated wet lay-up process where fabrication still requires manual hand labor in a $3 \mathrm{D}$ environment impeding productivity of composite product design advancement.

As an expert in the advanced composites field, I have developed fabrication skills with the use of machinery based on my past composite experience. In autumn 2011, the Korea government confirmed to fund my project. It is the development of a composite sanding machine. I began development of this semi-robotic prototype beginning in 2009. It has possibilities of replacing or augmenting the exhaustive and difficult jobs performed by human hands, such as sanding, grinding, blasting, and polishing in most often, very awkward conditions, and is also will boost productivity, improve surface quality, cut abrasive costs, eliminate vibration injuries, and protect workers from exposure to dust and airborne contamination. Ease of control and operation of the equipment in or outside of the sanding room is a key benefit to end-users. It will prove to be much more economical than normal robotics and minimize errors that commonly occur in factories. The key components and their technologies are a 360 degree rotational shoulder and a wrist that is controlled under PLC controller and joystick manual mode. Development on both of the key modules is complete and are now operational. The Korean government fund boosted my development and I expect to complete full scale development no later than 3rd quarter 2012.

Even with the advantages of composite materials, there is still the need to repair or to maintain composite products with a higher level of technology. I have learned many composite repair skills on composite airframe since many composite fabrication skills including repair, requires training for non aerospace applications.

The wind energy market is now requiring much larger blades in order to generate more electrical energy for wind farms. One single blade is commonly 50 meters or longer now. When a wind blade becomes damaged from external forces, on-site repair is required on the columns even under strong wind and freezing temperature conditions. In order to correctly obtain polymerization, the repair must be performed on the damaged area within a very limited time. The use of pre-impregnated glass fabric and heating silicone pad and a hot bonder acting precise heating control are surely required.
\end{abstract}

Keywords: Mechanical sanding, FRP(Fiber Reinforced Plastics), PLC, Semi-Robot, Composite Repair, Heat blanket, PID (Proportional Integral and Derivative) Control 


\section{Introduction}

Composite materials have been known throughout the history and they are discovered in people's daily lives. Manufacturing processes of composite materials have been evolved over the years including wet lay-up, filament winding, SMC/BMC, RTM, infusion, vacuum bagging, and others. The advancement of manufacturing process had led to quality enhancement, improvement in production speed, production cost reduction, and other benefits. However, when the time spent in each process is examined, the most time consuming processes are surface sanding, grinding, polishing, and others. These processes have required hand-operated sander by depending on workers' individual ability and senses in production sites. For this reason, uniform quality is hardly expected and rise in production costs is generated since only skilled and experienced works can perform such works. Furthermore, the process is considered as one of the most difficult jobs the decline in quality level is induced since novice workers take place of highly experienced composite technicians who do not work anymore due to aging and retirement. Turnover rate is quite high in this field. Consequently, handoperated sanding process by workers has reached the limitation due to the demands on fairly high flatness and continuous night shifts in large scale trends in composite materials. All of the manufacture and repair of composite materials is one of the critical issues in the factory and composite material components take up about $1 / 3$ of the production cost. Although robots were developed to replace challenging works of human, they have shortcomings of malfunctioning due to polluting agents such as dust and others. For this reason, robots require much cleaner work sites than human. The external surface of large vessels is coated with gel coat or paints. When the ship is sailing or anchoring, the gel coat or the coated layer could be damaged due to accumulation of foreign substances and outer stimulus such as rocks. Moreover, recoating process has to be repeated every two or three years due to water-induced electrolysis. Such maintenance process determines the most significant quality and greatly influences production costs. The development of the equipment replaces surface sanding process affecting the level of difficulty and the human body and it is the start (polishing of mater

\footnotetext{
*Corresponding author. Tel.: +82-51-410-4355, Fax.: +82-51-404-4355, E-mail address: yunhaek@hhu.ac.kr Copyright C KSOE 2012.
}

model surfaces) and end (polishing coated layer) of the manufacturing process, and takes up most of the working process in maintenance. Flat and simple curved surface is attainable in the initial phase and advancement of equipment is the ultimate goal to acquire by continuously resolving various issues.

\section{Examples of General Composite Material Sanding Process}

Equipment such as the initial robot (Fig. 2) will take place of multi-axis mechanical equipment controlled by hand tools (Fig. 1) and automated (PLC) or semi-automated control for surface treatment such as coating and polishing on large structures composed of reinforced plastics and metals.

\section{Development of Automated System of Envi- ronmental-Friendly Surface Sander for Large Structures (ROBOTHOs)}

\subsection{Product Characteristics}

- Utilized for various purposes including surface sanding, polishing, grinding, cutting, and others on various large structures

- Established the robotic system with 6 axes +2 passive axes replacing humans in inhospitable working site

- Prevents malfunction induced by pneumatic pressure generated from operation and electric control in polluted area

- Minimize trial and error by mainly using verified technology in the market

- Enhanced design, cost-competitiveness, accuracy, and durability by applying cutting-edge composite material manufacturing technology.

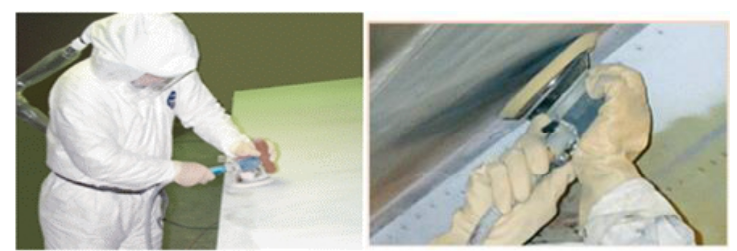

Fig.1 Basic concept map of wind turbine blade by automatic composition line

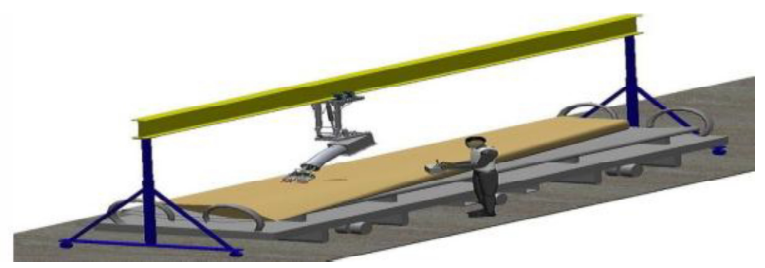

Fig. 2 Basic concept map of wind turbine blade by automatic composition line 


\subsection{Core Product Concept}

- Development of head module

- Development and analysis of caterpillar clutch and body

- Development and analysis of high-strength lightweight arms

- Development of dust-removing system installed with dust-collecting components, connecting device of related heads, and treatment

- Development of touch panel control system regulating movement of equipment by automatic or semi-automatic program
- Development of servo motor system for driving (forward/backward movement)

- Development of servo motor system for upward, downward, and body movement, and operation touch panel system program

\subsection{Manufacturing Process Cycle Utilizing ROBOTHOs}

- By implementing the invented ROBOTHOs system in the ordinary sanding process of $5,6,7$, and 8 , more effective results will be achieved in terms of time, cost and quality enhancement
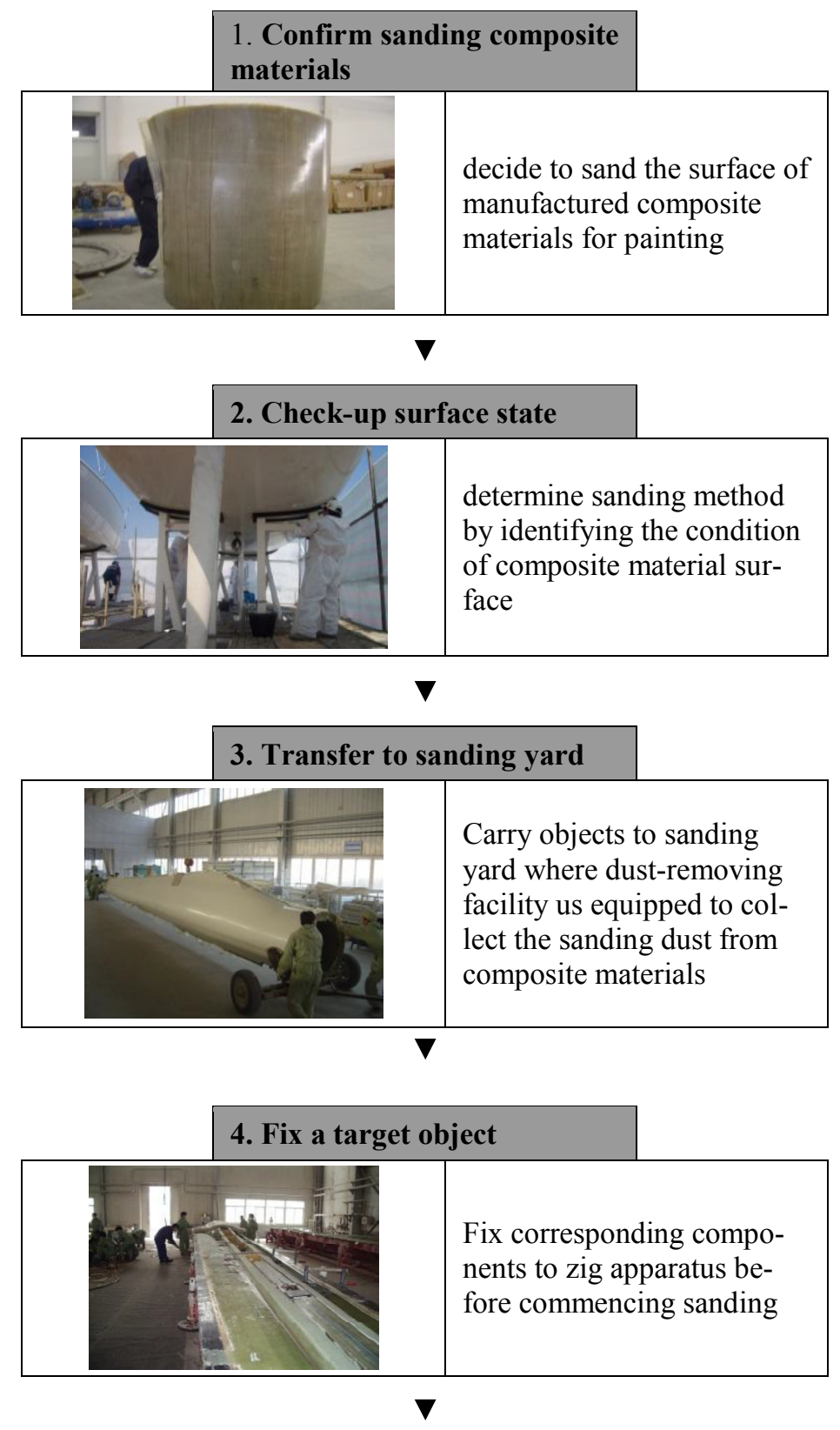


\section{Set the machine on zero}

$\boldsymbol{\nabla}$

\section{Input working program}

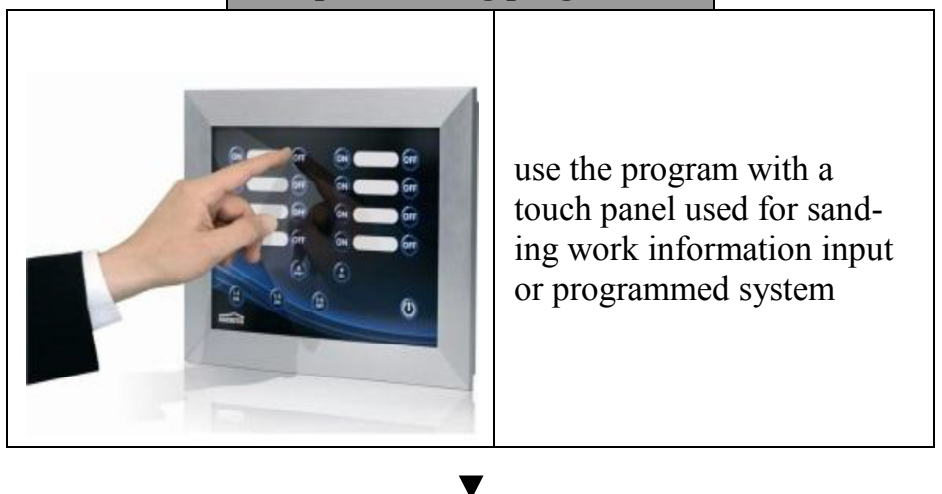

7. Operate the dust-collecting equipment

$\nabla$

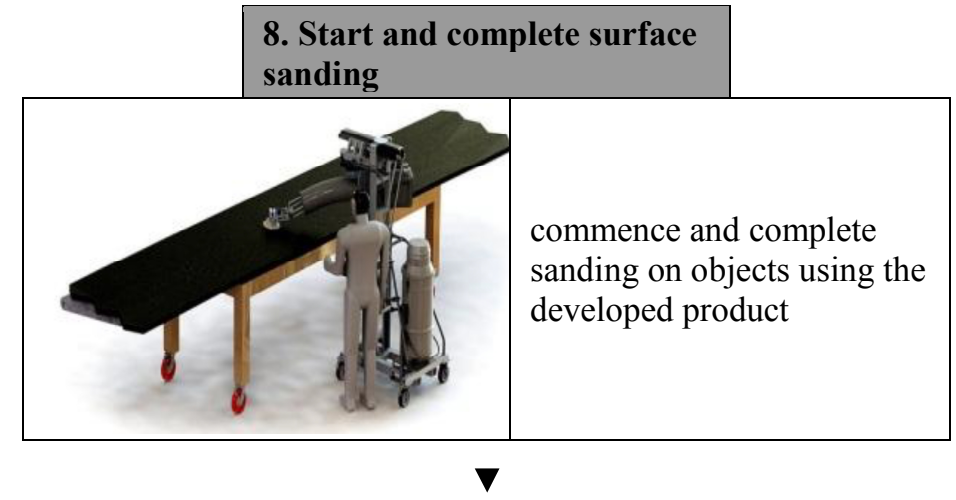

9. Turn off equipment

$\boldsymbol{\nabla}$

10. Check-up for work completion

$\nabla$

11. Disengage the zig apparatus

$\boldsymbol{\nabla}$

\section{Inspect the work quality}

$\nabla$

\section{Move to the next step}

Fig. 3 Process understanding with ROBOTHOs 


\section{ROBOTHOs Modeling and Static Analysis}

\subsection{Research Methods}

To develop the system, the product was designed based on the analysis of technology data at home and abroad. CATIA V5R was used as the 3D modeling program for static analysis. This research examined on interference impact, design error and others that could take place when the product is operated, prior to manufacture commencing. Structural durability and reliability were verified through such process.

\subsection{Modeling}

\subsubsection{Head Part Modeling}

3D models of head part are created using CATIA V5R as shown in Fig. 4. Modeling was initiated by different parts of the product. The impact of interference was examined through assembly as shown in Fig. 5 and no problem was detected. Spherical joint was attached to each side in the product manufacturing process for more stable sanding. Rotation inhibitor was attached to prevent spherical joint from rotation.

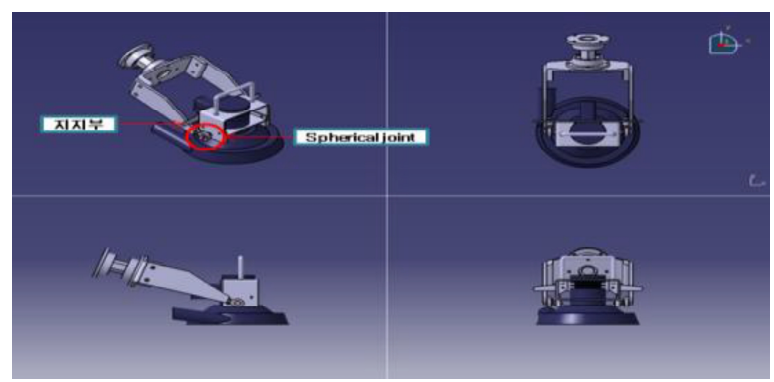

Fig. 4 Head part modeling

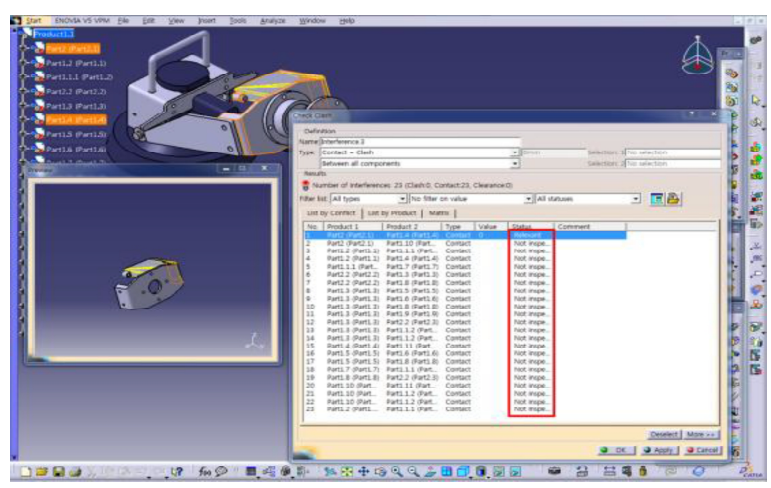

Fig. 5 Interference check in head part

\subsubsection{The Upper Body Part Modeling}

A 3D model of the upper body part is created using CATIA V5 $R$ as shown in Fig. 6. The $3 D$ is assembled with the 3D model of the head. The impact of interference was checked in the upper body part as shown in Fig. 7.

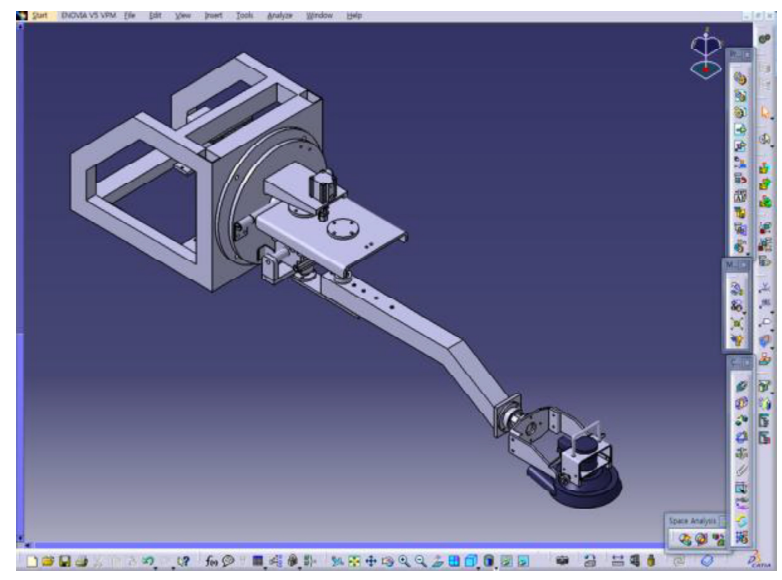

Fig. 6 The upper body part modeling

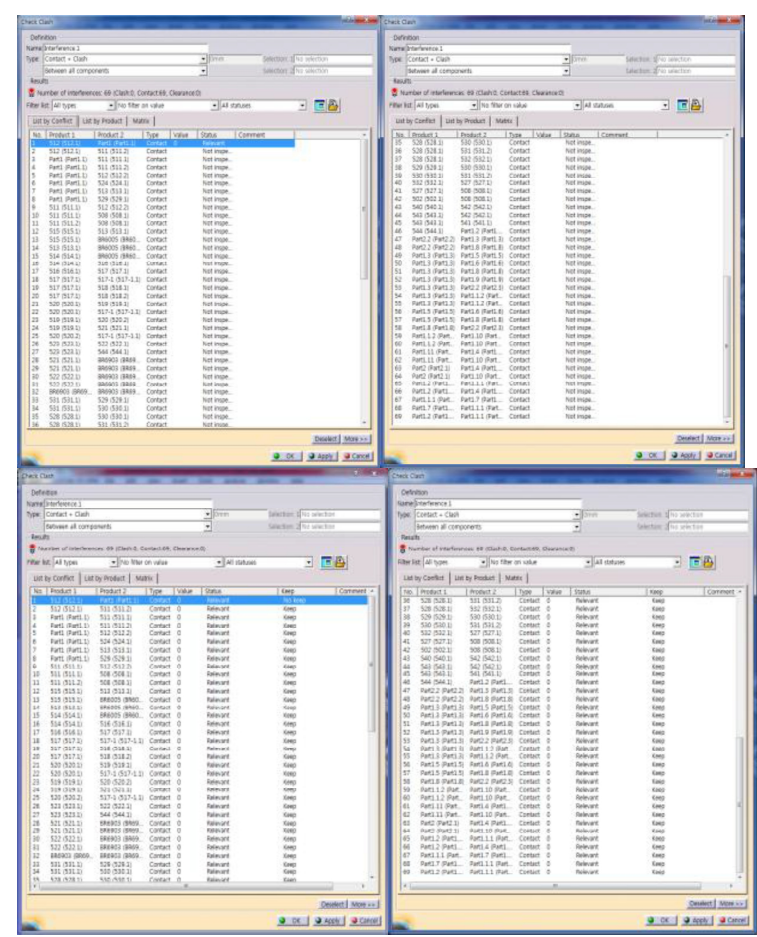

Fig. 7 Interference check in the upper body part 


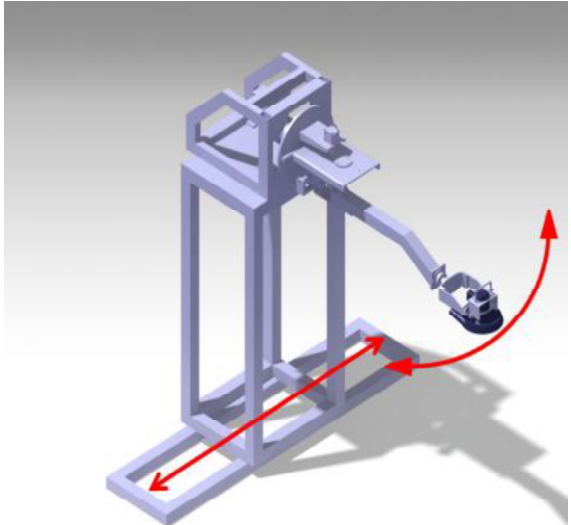

Fig. 8 The whole body configuration

\subsection{Static Structural Analysis}

\subsubsection{Restrain Condition}

Modeling of the head and the upper body part of the product was developed using CATIA V5 $\mathrm{R}$ and interference impact was investigated on each component. Subsequently, structural safety is secured and the presence of design error is identified. The static analysis of the verified model was conducted using the ANSYS program. One of the given conditions is that the other side of the head is fixed to the upper body part and another condition is that sanding of head part is carried out with a load of $15 \mathrm{~kg}$.

Table 1. admissible control input set

\begin{tabular}{c|c}
\hline \hline Material & Steel (yield strength $2.5 \mathrm{E}+008)$ \\
\hline A. & Fixed Condition \\
B. & $\begin{array}{c}\text { Impose a load of } 15 \mathrm{~kg} \text { similar to the } \\
\text { weight created when the sander is } \\
\text { pressed by a person } \\
\left(15 \mathrm{~kg} \times 9.81 \mathrm{~m} / \mathrm{s}^{2}=147.15 \mathrm{~N} \fallingdotseq 150 \mathrm{~N}\right)\end{array}$ \\
C. & $\begin{array}{c}\text { Create condition for frictionless with- } \\
\text { in spherical joint }\end{array}$ \\
\hline D. & Gravity condition \\
\hline \hline
\end{tabular}

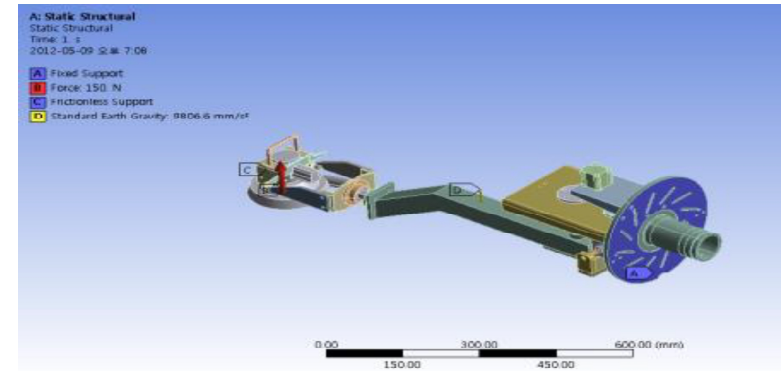

Fig. 9 Restrain Condition

\subsubsection{Setting up a Mesh}

Weaving high-quality mesh is extremely important in analysis. The size and the quantity of mesh have to be taken into consideration since accuracy is lowered when the mesh is too big. Moreover, analysis process takes longer when mesh is too much. The mesh was woven under default conditions without establishing the factor size as shown in Table 2. In overall, the size of mesh is large and its shape is inconsistent as shown below.

Fig.10 Setting up a mesh

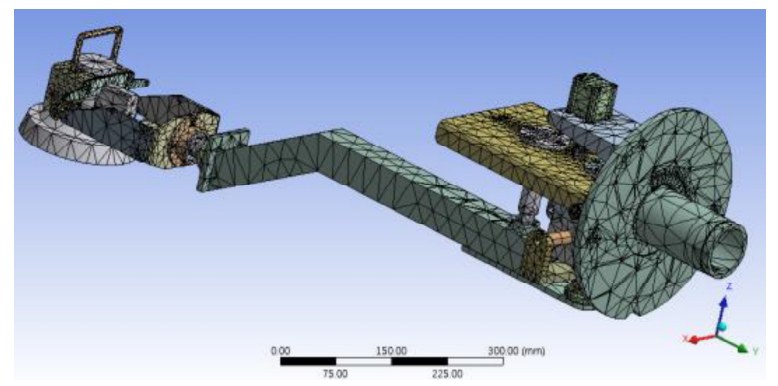

Mesh has been woven once again by setting the maximum size as $5 \mathrm{~mm}$ for the connected area of head where weight is imposed and the middle part of arms. Relatively insignificant factors have been excluded from the analysis. As a result, the total number of nodes has almost tripled enabling detailed analysis.

Fig. 12 is the result acquired through the static structural analysis. The developed product is well able to withstand stress imposed at the minimum of $3.6493 \mathrm{e}-6 \mathrm{MPa}$ to the maximum of $8.6873 \mathrm{e}-6 \mathrm{MPa}$. The yield strength of steel is considerably lower than $2.5 \mathrm{E}+008$, exhibiting comparative safety. The two figures shown below in Table 9 indicate three unsafe parts when stress is imposed unceasingly. Part (1) is joint area connecting arms and holding both sides of the arms as one in head. Part(2) is spherical joint and part (3) is the bent area of arm part. 
Byung-keun Choi, Yun-hae Kim, Jin-cheol Ha, Jin-woo Lee, Jun-mu Park,

Soo-jeong Park, Kyung-man Moon, Won-jee Chung and Man-soo Kim

International Journal of Ocean System Engineering 2(3) (2012) 185-194

Table 2. Mesh setting

\begin{tabular}{c|c}
\hline \hline Maximum Mesh Size & Default(setup X) \\
\hline Minimum Mesh Size & $0.67 \mathrm{~mm}$ \\
\hline Total Number of Nodes & 89965 \\
\hline Total Number of Mesh & 42857 \\
\hline \hline
\end{tabular}
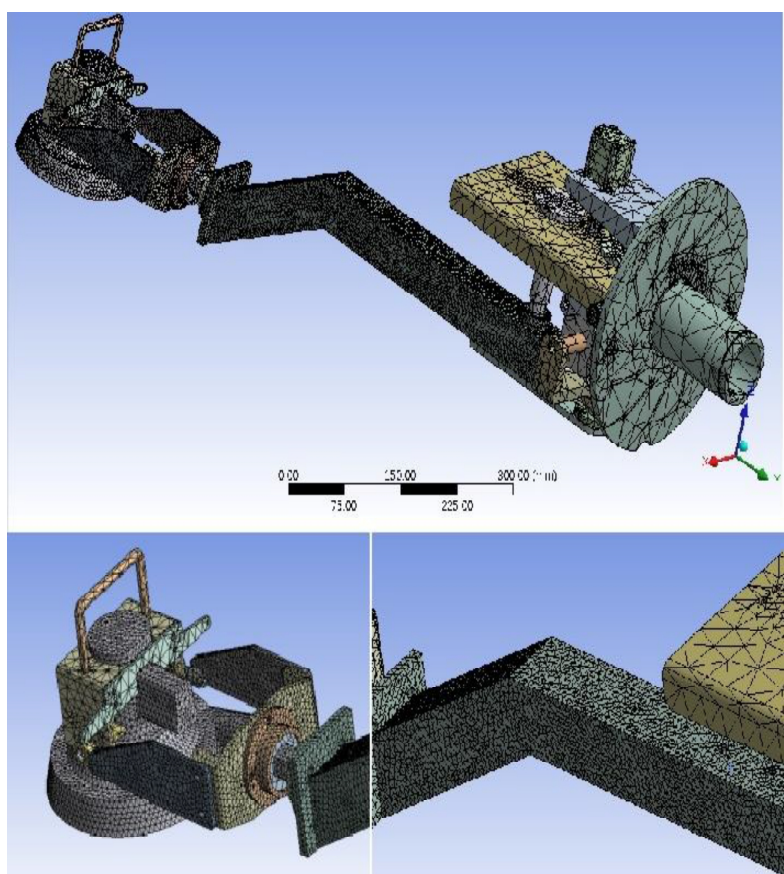

Fig. 11 Setting up a mesh

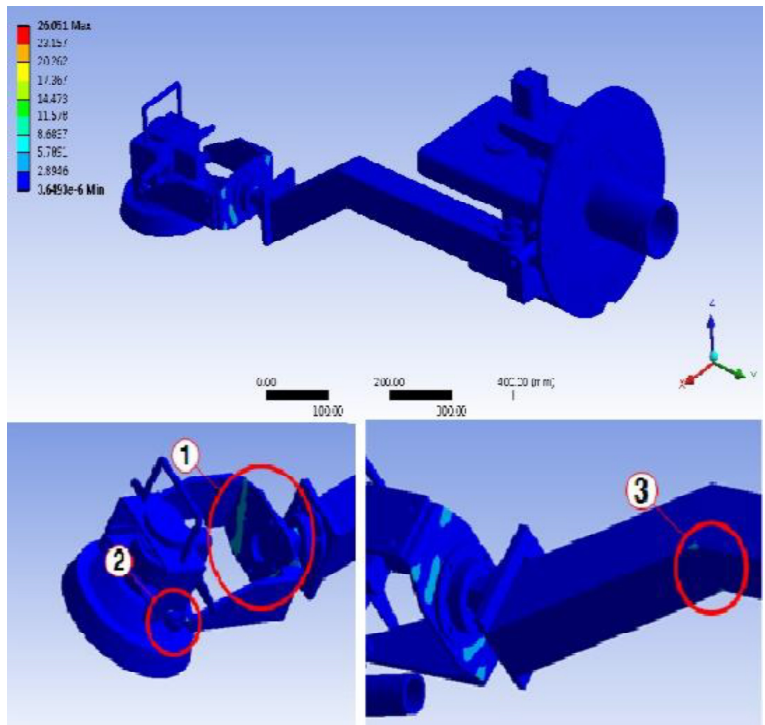

Fig. 12 Static Analysis Results

Fig. 13, 14, and 15 shown below are the analysis results of (1), (2), and (3) parts in Fig. 12. The maximum stress of each part was 5.3212MPa, 16.574MPa, and 4.6892MPa, respectively.
Table 3. Mesh setting

\begin{tabular}{c|c}
\hline \hline Maximum Mesh Size & $5 \mathrm{~mm}$ \\
\hline Minimum Mesh Size & $0.67 \mathrm{~mm}$ \\
\hline Total Number of Nodes & 268894 \\
\hline Total Number of Mesh & 151506 \\
\hline \hline
\end{tabular}

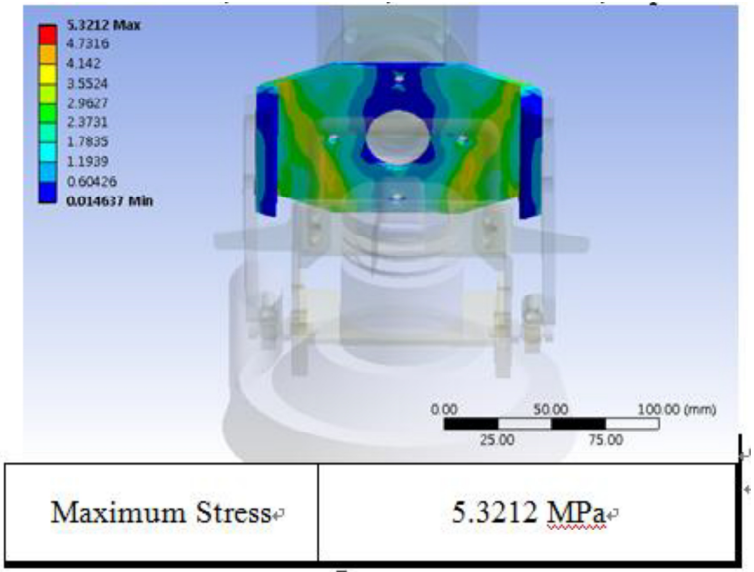

Fig. 13 Analysis of part (1)

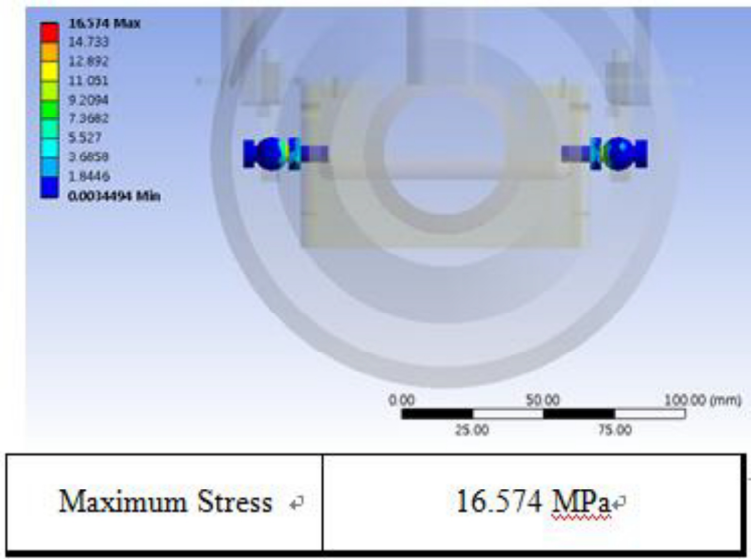

Fig. 14 Analysis of part (2)

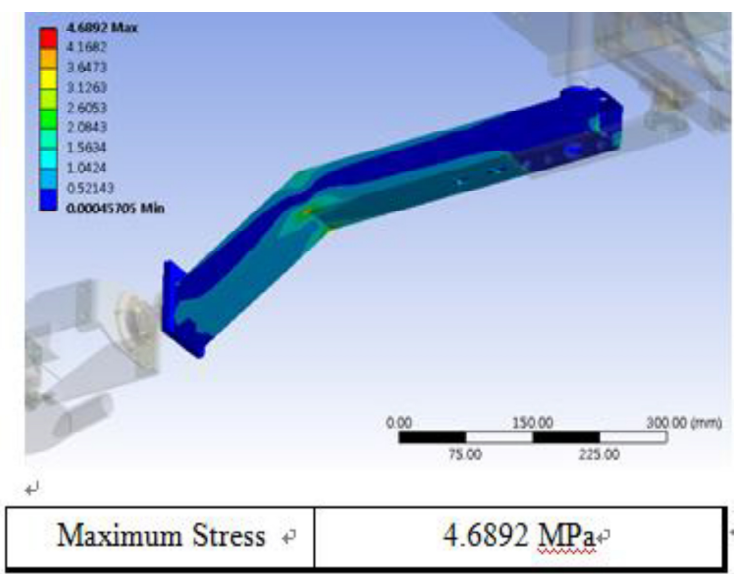

Fig. 15 Analysis of part (3) 


\subsubsection{Safety Factor}

The overall safety factor of the invention has been examined based on the analysis results. The safety factor is 9.5965 , indicating that the product is greatly safe.

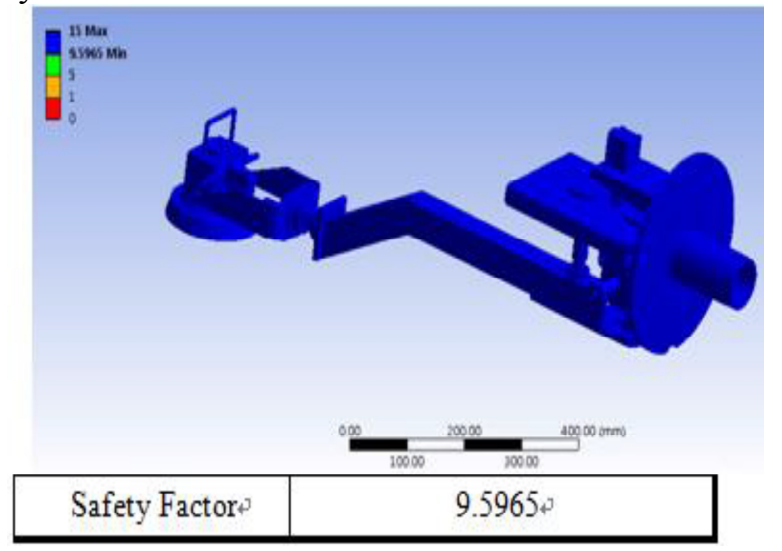

Fig. 16 Safety Factor

\section{Competitiveness of ROBOTHOs}

The surface sanding system currently uses sanding method using hand tools domestically. Since development of equipment and production are keep separately even in the manufacturing design, surface sanding accounts for only a small part in the overall production process. For this reason, related domestic industries hardly invest in technology development in this sector. On the contrary, the current state of technology development is quite the opposite in overseas. Temple Allen Industries Inc., in the United States has already developed automated sanding system, called EMMA. The product was released in 2007 and it has been supplied to the Boeing 737 Rudder shop factory in Washington for painting after sanding the wing surface of passenger aircraft. Likewise, ROBOTHOs developed in our company have been compared with other products based on the commercialized surface sanding system data in terms of quality, technology, cost and other criteria.

Functionalities of ROBOTHOs are outstanding in technological sector as shown in Table when it is compared with products of competitors in home and abroad in terms of quality, technology, price, and other categories. Dust collecting equipment attached ROBOTHOs enables unmanned production more efficiently due to the enhancement of apparatus technology with long-term effect. Surface sanding in overall manufacturing process enables technology enhancement by sanding equipment and to overcome hand-arm vibration syndrome (HAVS) of workers. Maximization in productivity will be realized by securing production line setup in working space of ROBOTHOs. Moreover, high-quality production is anticipated through increase in product-related allowance and improvement in coated surface, since sanding by equipment substantially enhances degree of surface and flatness. ROBOTHOs are the product manufacturing by integrating IT technology. Maintenance technology of ROBOTHOs is more outstanding compare to surface sanding system using EMMA or hand tools because it uses transmitting method by utilizing internet-controlled program in surface maintenance of equipment including large structures. 
Table 4. The Comparison of Surface Sanding Systems

\begin{tabular}{|c|c|c|c|}
\hline \multirow[b]{2}{*}{ Items } & $\begin{array}{l}\text { Company's Product } \\
\text { (ROBOTHOs) }\end{array}$ & $\begin{array}{l}\text { Overseas Product } \\
\text { (EMMA) }\end{array}$ & $\begin{array}{c}\text { Hand Tool } \\
\text { (Sander) }\end{array}$ \\
\hline & & & \\
\hline $\begin{array}{l}\text { Dedicated Dust } \\
\text { Collector }\end{array}$ & YES & NO & NO \\
\hline $\begin{array}{l}\text { Automatic Con- } \\
\text { troller }\end{array}$ & YES(PLC+Touch Screen) & only joystick & N/A \\
\hline $\begin{array}{l}\text { Productivi- } \\
\text { ty(Times) }\end{array}$ & 15 & $7-10$ & 1 \\
\hline Total Weight & 1 & 1.3 & $\mathrm{~N} / \mathrm{A}$ \\
\hline $\begin{array}{l}\text { Number of Ma- } \\
\text { chines }\end{array}$ & 1 & 2 or above & $\mathrm{N} / \mathrm{A}$ \\
\hline $\begin{array}{l}\text { Production } \\
\text { Site(Rail) }\end{array}$ & indoor/outdoor & only indoor & N/A \\
\hline Width & $2 \mathrm{~m}$ or above & $1.2 \mathrm{~m}$ & $\mathrm{~N} / \mathrm{A}$ \\
\hline $\begin{array}{l}\text { Unmanned Pro- } \\
\text { duction }\end{array}$ & Yes & No & No \\
\hline $\begin{array}{l}\text { Additional Fa- } \\
\text { cility Investment }\end{array}$ & rail on the floor & installed on a ceiling & N/A \\
\hline $\begin{array}{l}\text { Quality Ad- } \\
\text { vancement }\end{array}$ & very high & low & N/A \\
\hline Cost & Below 1000 million & $\begin{array}{c}\text { 1200million }+ \text { line setup } \\
\text { cost }\end{array}$ & N/A \\
\hline $\begin{array}{l}\text { Personal Protec- } \\
\text { tion Equipment }\end{array}$ & No & YES & YES \\
\hline
\end{tabular}

\section{Conclusion}

From economic and industrial aspects, ROBOTHOs, the automated system developed as environmental-friendly surface sander is suitable for creating a new market in various large structures such as wind turbine, aircraft, military equipment, railway vehicles, buses, shipbuilding, and others, as well as 3D work environment. Productivity could be enhanced up to 7-10 times at most compare to hand tools. Expendable ex- penses could be reduced by saving investment cost for large-scale dust facility, decreasing expenses created due to defective products, and prolonging the life of sand papers by integrating portable dust collectors.

Consequently, these contribute strengthening cost-effectiveness by enhancing productivity. Rapid growth in large structures manufacturing industry is anticipated to lead to sales growth by coordinating to $3 \mathrm{D}$ work environment as techno- 
logical perfection of ROBOTHOs advances with the appearance of new markets such as wind turbine manufacturing industry. An increase in export is expected by integrating with domestically outstanding machinery industry infrastructure aiming for productivity enhancement.

Moreover, equal job opportunity will be provided to all walks of life regardless of gender based on the unmanned production technology. Furthermore, one of the challenges for advancement of ROBOTHOs is searching for a business partner who could take charge of component standardization, international standardization, and modulation.

In addition, more practical studies have to be conducted on the precise motion and expansion of its arm for the additional technology development in the future.

\section{Acknowledgements}

This research was supported by the MKE(The Ministry of Knowledge Economy), Korea, under the ITRC(Information Technology Research Center) support program supervised by the
NIPA(National IT Industry Promotion Agency)(NIPA-2012-C1090-1221-0015)

\section{References}

[1] K.S. Fu, R.C. Gonzalez, C.S.G. Lee (1987). Robotics. Mc Graw Hill

[2] TSNE operation division (2011). ANSYS WORKBENCH. Sigmapress.

[3] J.Y. Ko (2009). ANSYS \& Finite Elements Method. Sigmapress.

[4] A. Lekatou, S.E. Faidi, D. Ghidaoui, S.B. Lyon and R.C. Newman. Composites Part A 28 (1997), pp. 223-236.

[5] Srivastava V K and Hogg P J 1998 J. Mater. Sci. 331129.

[6] Y. H. Kim, K. J. Kim, J. W. Han, Y. D. Jo, S. Y. Bae, K. M. Moon, and D. H. Kim, The Korea Society for Composite Materials 21, 1 (2008).

[7] Y. H. Kim, K. J. Kim, J. W. Han, Y. D. Jo, S. Y. Bae, and K. M. Moon, The Korea Society for Composite Materials 21, 8 (2008).

[8] Y. H. Kim, S. H. Eum, C. W. Bae, J. W. Han, K. J. Kim, and Y. D. Kim, Advanced Composite Materials 19, 55 (2010). 